\title{
Antimicrobial or Acidified/Chlorinated Water During Husbandry Indicator
}

National Cancer Institute

\section{Source}

National Cancer Institute. Antimicrobial or Acidified/Chlorinated Water During Husbandly

Indicator. NCl Thesaurus. Code C158363.

An indication as to whether the animal received antimicrobials or acidified/chlorinated water during husbandry. 